\title{
Pearls for Practice
}

\section{Health Information Needs of the Pregnant Adolescent}

\begin{abstract}
Adolescent pregnancy is a major problem in the United States. Despite its leadership among industrialized countries, the United States falls far short of others in its handling of this issue. This article describes a project that is intended to empower the adolescent to care for herself during her pregnancy. The project suggests a more interactive approach to care. The nurse practitioner serves as a guide to pairs of pregnant adolescents who learn the skills necessary to participate in their care. Educational needs are met through the use of group sessions and cards designed for each trimester. The project is described briefly in the article, along with appropriate use of the pregnancy information cards. The use of these cards has proven effective with the adolescent and also serves to increase the involvement of the older woman in her care. The role of the nurse practitioner is paramount in the process.
\end{abstract}

\section{CONTEXT}

In the United States today, adolescent pregnancy is a problem with tremendous social and economic impact. Approximately one million teens become pregnant each year, resulting in nearly 500,000 births, 180,000 of which are to teens under the age of 18 (Wildey, 1987). The risks associated with adolescent childbearing are many, affecting every aspect of health, life, and wellbeing of the young woman and her infant. The pregnancy also affects the partner and the young woman's family (McAnarney \& Greydanus, 1989). The healthy adolescent is at risk from the following: lack of early intervention due to late onset of prenatal care, low birth weight infants, preterm labor, preeclampsia, preterm rupture of membranes, etc. (Gale, Zengen, Harlap, Fischer, \& Sevenson, 1988; McAnarney \& Greydanus, 1989). Children born to adolescent mothers who do not receive adequate prenatal care are three times more likely to be low birth weight and much more likely to die before their first birthday than those whose mothers received adequate prenatal care (Machala \& Miner, 1991).

The pregnant adolescent is often at a significant social and economic disadvantage, which may impair her ability to obtain adequate prenatal care. Many pregnant teenagers have a history of poor school attendance and achievement, troubled family relationships, experiences with family violence, and exposure to drug abuse (Palmore \& Shannon, 1988). More than half of adolescent mothers raise their children alone. Many teenage mothers are faced with the task of providing for their children with minimal family support and an education of less than high school equivalency (Palmore \& Shannon, 1988). Studies suggest that a woman's well being is directly related to her level of schooling. A high school dropout can expect no more than $\$ .70$ for every dollar earned by a high school graduate (Children's Defense Fund, 1986).

With all the significant factors impacting a pregnant adolescent's life, prenatal care does not have a high priority (Makinson, 1985). Yet research has demonstrated that pregnant adolescents who receive early and consistent prenatal care are at no greater risk for increased mortality and morbidity than are comparable adult women (Hofferth, 1987; McAnarney \& Greydanus, 1989). Additionally, the literature indicates that emphasis on education, adequate nutrition, and continuity of care lead to improved maternal weight gain, a decrease in low birth weight infants, decreased anemia, and a lower incidence of hypertensive disorders of pregnancy. Prenatal care, therefore, has become the mainstay of efforts to prevent poor pregnancy outcomes in the adolescent.

The puzzle of how to ensure comprehensive prenatal care to the high-risk adolescent population has confounded the health care community for over two decades. Virtually every state in the nation has initiated some type of program designed to address this tre- 
mendous problem. Most have met with limited success. Infant mortality rates have plateaued, teenage pregnancy rates are rising exponentially, and even in areas where access to prenatal care is assured, teenagers are still not receiving what the American College of Obstetricians and Gynecologists would define as "adequate" prenatal care (Mason, 1991).

In an effort to reverse this trend, many health care organizations are turning their attention to prenatal clinics and programs that focus specifically on adolescents and their unique needs (Hardy, King, \& Repke, 1987; Slager-Earnest, Hoffman, \& Beckman, 1987). Health education programs for the client are designed to increase motivation and compliance in a manner that is developmentally appropriate to the target audience (Boston Women's Health Book Collective, 1979).

During adolescence, group membership is of paramount importance. Peer groups allow for transient sources of feedback, for feelings of security and worth, and for support and encouragement during a time when the individual is gradually drawing away from the family and becoming more self-reliant (Erikson, 1964). For this reason, a prenatal care program that emphasizes the importance of the peer relationship would seem a logical direction for prenatal care.

This paper describes a demonstration project that uses the developmental dependence of adolescents on peers to foster compliance with prenatal care.

\section{DEMONSTRATION PROJECT}

In January 1990, the Southeast Michigan Chapter of March of Dimes funded a pilot program for a nurse practitioner-run adolescent peer support group during pregnancy. The program was set up in two HMO clinics in the greater Detroit area. The researchers hypothesized that adolescents in the program would have increased compliance with the prenatal care regimen and thus have better perinatal outcomes than adolescents who were not part of the program. It was also anticipated that the innovative approach to care with peers would increase self-concept and empowerment in the teens. As part of this project, an educational program was designed.

In order to set up the program, issues regarding teaching methodology and materials that best address the adolescents' needs had to be considered. The principles of teaching-learning theory were examined, and a program was developed based on Redınan's (1984) three domains of learning: cognitive, affective, and psychomotor.

With this program, the adolescents learned to understand (cognitive) specifics of pregnancy such as fetal growth and development and personal care. All materi- als were adapted to a third grade reading ability using the Fry (1968) graph for estimating readability. This technique involves selecting three 100-word passages from various locations in the printed materials. First, the total number of sentences in each passage is counted; then, the total number of syllables is assessed for each passage. These results are then averaged and plotted on a graph to determine readability. Drawings and diagrams were added to the cards where appropriate. Pictorial learning was found to be superior to verbal learning and equivalent to the learning that takes place with printed materials (Redman, 1984). The use of pictures and diagrams also served to make the cards more "eye-catching," thus increasing their appeal. The intention was to optimize the teen's involvement and empower her to be active in her own health care.

The affective domain was addressed by emphasizing personal acceptance of pregnancy and promotion of positive self-worth through role modeling and mastery. Adolescent self-concept was monitored before and after the delivery. Additionally, mastery of the labor and delivery experience was assessed.

Content in the psychomotor domain focused on developing motor skills that the adolescent could then use in her own pregnancy. These programs included teaching pairs of teens to help with the critical measures that are a part of routine prenatal care; i.e., urinalysis, blood pressures, weights, fundal heights, and fetal heart tones. Adolescents learned these measurements under the direct supervision of a nurse practitioner.

\section{PRACTICE}

While the particular focus of this project was the pregnant adolescent, the program materials and approach can be used with any age group. The sharing of skills does involve the individual and allows her to feel more in control of her pregnancy.

Information cards were one of the tools designed to disseminate information to the adolescents. According to Redman (1984), the use of written educational materials offers many advantages over verbal presentation of the same material. Verbal information alone is often overwhelming and may be forgotten by the patient after the clinic visit. Printed material has been described as "frozen language" (Redman, 1984). In written format, the information is constantly available to the reader, thus decreasing confusion and reinforcing learning. Printed materials relax time requirements and are more efficient than oral language for most learners, because the reader controls the speed of comprehension. Most 
experts consider printed material ideal for communicating complex information that incorporates definitions, qualifications, lists, complex concepts, or relationships (Redman, 1984).

The principal investigator determined that the use of a card format would be more appealing, durable, and marketable than the standard handouts usually printed on paper. For this reason, the health information was placed on brightly colored cards that were color coded for each trimester. Additional cards were designed to allow the client to maintain her own prenatal measurement record, to plot her weight, and to allow her to anticipate timing of routine lab tests.

The cards were designed to fit in a box measuring 3 in. wide by $9 \mathrm{in}$. long. Cards were given to the client when checking in for her prenatal appointment, thus encouraging use while waiting for the practitioner. The information would be fresh in the mind during the prenatal appointments, stimulating the client to address her concerns and prompting her to ask knowledgeable questions. The cards served to standardize information and to be sure that all important information was covered.

The clients in the pilot study had input into the content of the cards. The materials dealt primarily with common issues and concerns voiced through prenatal visits. Additional topics, deemed appropriate by the investigators, were also included.

Each set of cards consisted of the danger signs, growth and development of the fetus, and bodily changes in the mother, as well as discomforts in pregnancy. The first trimester cards (Figure 1) also included:

- a record of prenatal visit parameters (blood pressure, fundal height, fetal heart tones, etc.);

- a list of common tests and appropriate visits, with room to record results;

- a weight grid to allow the client to plot her weight gain;

- emphasis on the importance of prenatal care;

- maternal nutrition issues; and

- exercise limitations.

The second trimester cards included such topics as:

- ultrasound and special lab tests;

- preterm labor signs and methods of prevention; and

- childbirth education.

The final packet of cards addressed the following:

- preparation for labor;

- labor precautions;

- advantages of breast feeding and bottle feeding, as well as "how to" issues;

- parenting;

- preparation for the hospital;

- infant care; and

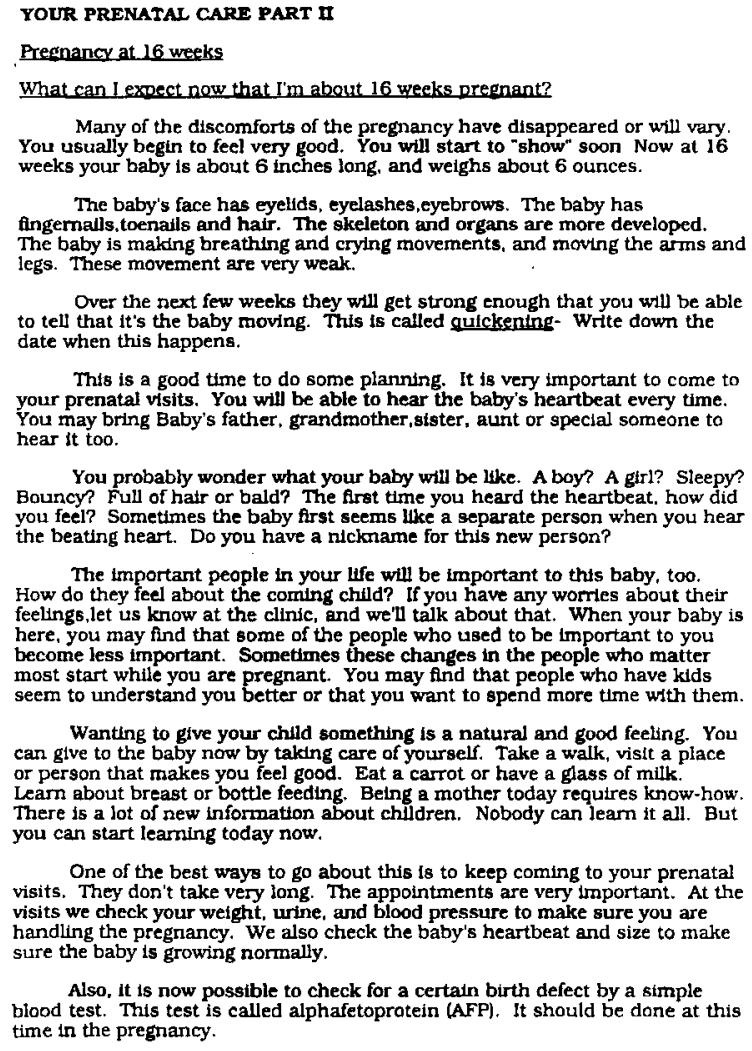

Over the next few weeks they will get strong enough that you will be able to tell that it's the baby moving. This is called quickening- Write down the date when this happens.

This is a good time to do some planning. It is very important to come to your prenatal visits. You will be able to hear the baby's heartbeat every time. hear it too.

You probably wonder what your baby will be like. A boy? A girl? Sleepy? Bouncy? Full of hatr or bald? The frat time you heard the heartbeat. how did

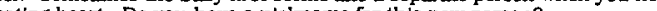

The important people in your life will be important to this baby, too. How do they feel about the corning child? if you have any worrles about their feelings, let us know at the clindc, and we'll talk about that. When your baby is here. you may find that some of the people who used to be important to you become less important. Sometimes these changes in the people who matter most start while you are pregnant. You may find that people who have kids
seem to understand you better or that you want to spend more tme with them.

Wanting to give your chlld something is a natural and good feeling. You can give to the baby now by taking care of yourself. Take a walk, visit a place or person that makes you feel good. Eat a carrot or have a glass of milk. Leam about breast or bottle feeding. Being a mother today requires know-how. you can start learning today now.

One of the best ways to go about this is to keep coming to your prenatal visits. They don't take very long. The appointments are very important. At the handling the presnancy. We also check the baby's heartbeat and size to make sure the baby is growing normally.

Also, it is now possible to check for a certain birth defect by a simple biood test. This test is called alphafetoprotein (AFP). It should be done at this time in the pregnancy.

FIGURE 1

- postpartum changes in the hospital and at home.

Additional cards, included in all the sets, showed the weight and length of the baby during each month of the trimester. Word search puzzles for each section added to the potential learning and increased the interest level of the younger mothers.

Based on the usefulness of these cards in working with the teen support group and other clients, we developed a second set of cards for high-risk issues. Topics for this group of cards were selected by the principal investigators. These cards were limited to high-risk situations encountered frequently in the teenage population, as well as situations commonly associated with poor pregnancy outcomes. The cards were given a distinguishing color different from the original cards. They were further divided into the trimester in which they most commonly occurred. The first trimester cards included hyperemesis, multiple gestation, spotting or bleeding early in pregnancy, substance use, and sexually transmitted diseases. The second trimester cards included urinary tract infections, gestational diabetes, pregnancy-induced hypertension, and anemia. In the third trimester packet were vaginal birth after cesarian section, post-term pregnancy, intrauterine 


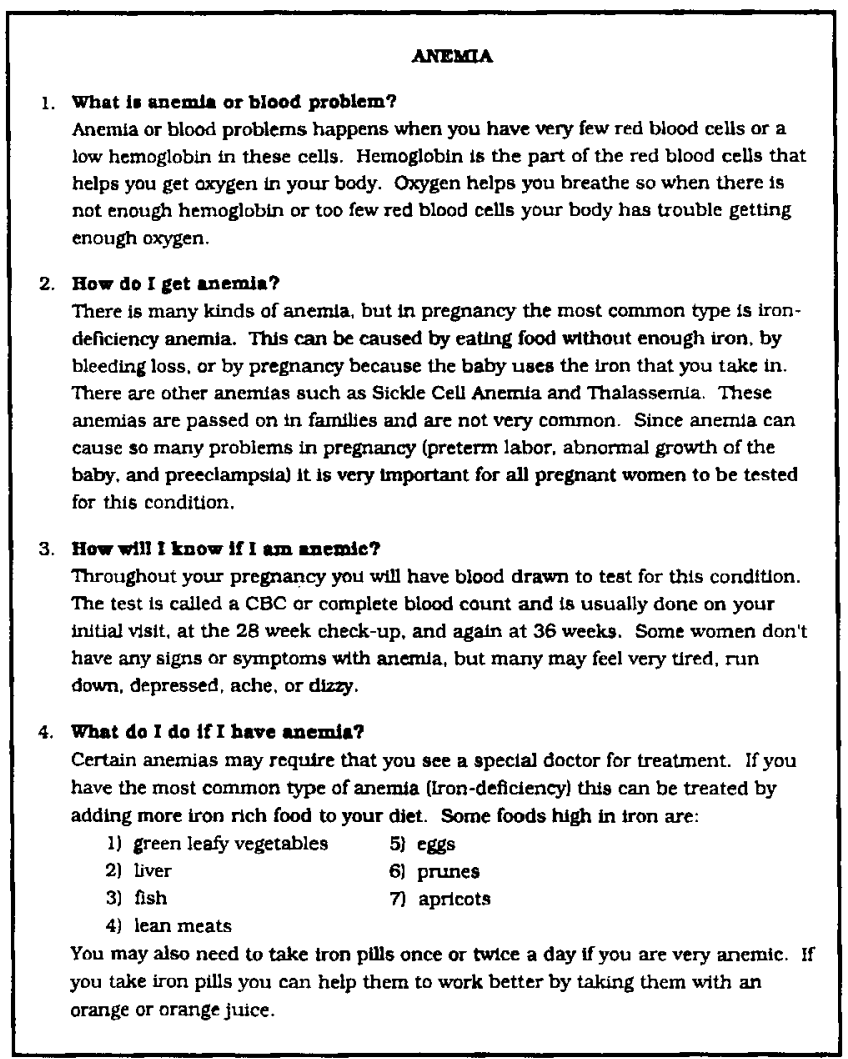

FIGURE 2.

growth retardation, postpartum infection, and postpartum depression. A sample of these cards is shown in Figure 2.

Documentation of the education process (including distribution of the pregnancy education cards) was accomplished systematically. During the initial obstetric interview, the clients were acquainted with the card system. They were given the appropriate set or sets of cards, and a notation was made on the pregnancy education record kept with the chart (Figure 3 ). The clients also received a card showing the pregnancy education record so they were able to follow along with the information they should be receiving during each visit. This provided an additional set of checks and balances for the practitioner. This approach served to involve the client more totally in her care. The end result was both continuity of care and a better educated client.

\section{IMPLICATIONS FOR PRACTICE}

Pregnancy during adolescence may have a negative impact upon the teenager's health and that of her infant. Therefore, decisions about how best to provide care to this high-risk population should be of paramount importance to maternal/child health practi-

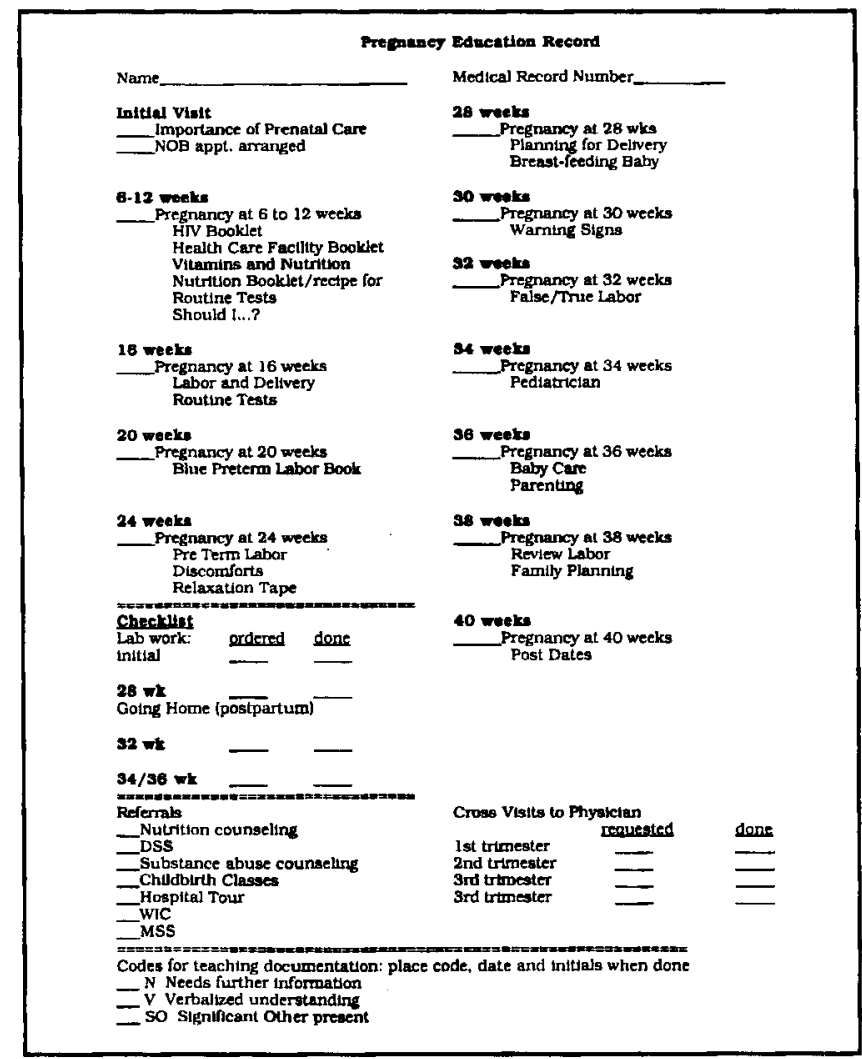

FIGURE 3

tioners. The use of pregnancy information cards is an efficient, effective, and relatively inexpensive way to provide teens with the knowledge and skills they need to ensure optimum pregnancy outcomes.

There is much to be gained by improving our delivery of prenatal care to the adolescent population. The reduction of infant morbidity and mortality could greatly reduce health care costs, as could the prevention of repeat teen pregnancies. In addition, adequate prenatal care programs could lessen the impact of adolescent motherhood. Emphasis on practice in this high priority area results in an individual more confident and capable of coping with the unique demands of being a teenage mother. The cards also empower other women to be more in charge of their pregnancies. The knowledge shared and the confidence demonstrated will help women in general and teenagers in particular to be interactive health consumers. This type of information is easy to distribute and assures quality and consistency in the practitioner's education of her client.

Paulette J. Hoyer, PhD, RN,C University of Michigan School of Nursing, Division II Women's Health Program Ann Arbor, MI 
Mary Jacobson, MSN, RN,C Adjunct Faculty

OB/GYN Nurse Practitioner Metropolitan Health Care

Ann Arbor, MI

Kimberly Addison, BSN, RN,C Graduate Student

Women's Health Nurse Practitioner Program University of Michigan Ann Arbor

Sandra Dupre, MS, RN,C Graduate Nurse Practitioner Women's Health Nurse Practitioner Program

Ann Arbor, MI

\section{References}

Boston Women's Health Book Collective. (1992). The new our bodies, ourselves (4th ed., pp. 400-415). New York: Simon and Schuster.

Children's Defense Fund. (1986). Adolescent pregnancy: Whose problem is it? Washington, DC: Author.

Erikson, E. H. (1964). Childhood and society (2nd ed., pp. 481-497). New York: Norton.

Fry, E. (1968). A readability formula that saves time. Journal of Reading, 514, 577

Gale, R., Zengen, S., Harlap, S., Fischer, A., \& Sevenson, D. (1988) Birth out of wedlock and the risk of intrauterine growth retardation. American Journal of Perinatology, 5, 278-282

Hardy, J., King, T., \& Repke, J. (1987). The Johns Hopkins adolescent pregnancy program: An evaluation. Obstetrics and Gynecology, 69, 300-306.

Hofferth, S. L. (1987). The children of teen childbearers. In National Research Council (Eds.), Risking the future: Adolescent sexuality, pregnancy and childbearing (pp.174-206). Washington, DC: National Academic Press.
Ellen Morin, MS, RN,C

Graduate Nurse Practitioner

Women's Health Nurse Practitioner Program

Ann Arbor, MI

Susan Belknap, BSN

Graduate Student

Women's Health Nurse Practitioner Program

University of Michigan

Ann Arbor

Machala, M., \& Miner, M. (1991). Piecing together the crazy quilt of prenatal care. Public Health Reports, 106, 353-359.

Makinson, C. (1985). The health consequences of teenage fertility. Family Planning Perspectives, 17(3), 132-139.

Mason, J. O. (1991). Reducing infant mortality in the United States through "Healthy Start." Public Health Reports, 106, 479-483.

McAnarney, E. R., \& Greydanus, D. E. (1989). Adolescent pregnancy and abortion. In A. Hoffman \& D. Greydanus (Eds.) Adolescent medicine (pp. 444-462). Norwalk, CT: Appleton and Lange Publishers.

Palmore, S., \& Shannon, M. (1988). Risk factors for adolescent pregnancy students. Pediatric Nursing, 14, 241-245.

Redman, B. (1984). The process of patient teaching in nursing (4th ed. pp. 62-91). St. Louis, MO: C.V. Mosby Company

Siager-Earnest, S., Hoffman, S., \& Beckman, C. (1987). Effects of a specialized prenatal adolescent program on maternal and infant outcomes. Journal of Obstetric. Gynecologic, and Neonatal Nursing, 16, 422-429.

Wildey, L. S. (1987). Diagnosis and initial management of the pregnant adolescent. Journal of Pediatric Health Care, 1, 60-64. 